\title{
Modeling of Heat Transfer from a Horizontal Tube Immersed in a Shallow Gas Fluidized Bed
}

\author{
Dr. burhan Mahmood Al-Ali \\ Assistant Professor \\ Asma'a Taha Hussin \\ Department of Mechanical Engineering, College of Engineering, University of Mosul
}

\begin{abstract}
In this study, modeling of heat transfer from a horizontal tube immersed in a shallow gas fluidized bed was investigated. The Surface Particle Emulsion heat transfer model SPE and the single particle model were used in the present work as theoretical models to calculate the average heat transfer coefficient at the tube surface. On the basis of sectorizing the surface of the tube into the three sections (top, side and bottom), The SPE model was used for the top section of the tube and the single particle model was used for the side and bottom of the tube. The experimental work involved measuring particle residence time at the heat transfer surface by using a $30 \mathrm{frame} / \mathrm{sec}$ digital camera, and the bubble frequency was used as a measuring tool for predicting the particle residence time at the transfer surface. The results obtained show that the average heat transfer coefficient increases with the decrease in particle diameter and the increase in the height of the tube above the distributor plate, while tube size has a small influence on average heat transfer coefficient. The calculated results obtained from the models agreed reasonably well with experimental data.
\end{abstract}

\footnotetext{
نمذجة انتقال الحرارة من انبوب افقي مغمور في طبقة مميعة غازية ضحلة

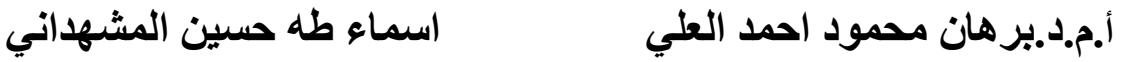

تم في هذا البحث دراسة نمذجة انتقال الحرارة من أنبوب أفقي مغمور في طبقة مميعة غازيـة ضحلة.استخدم في هذا

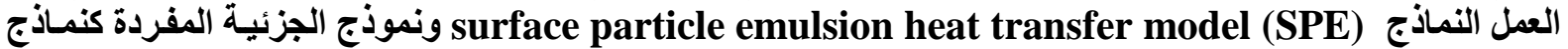

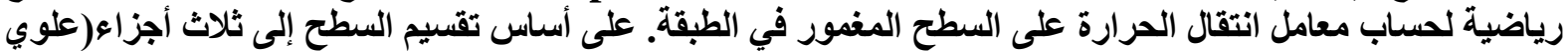

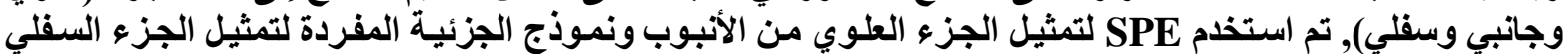

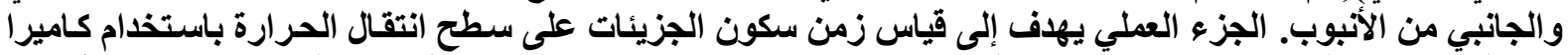

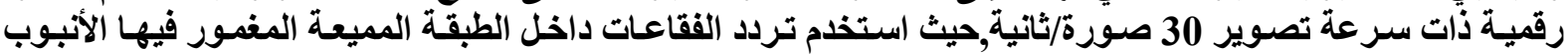



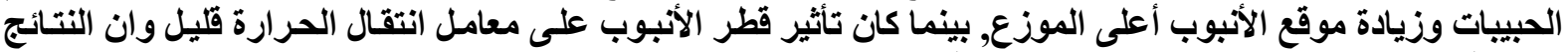
النظرية تطابقت بشكل مقبول مع النتائج العملية.
} 


\section{Introduction}

Fluidization is a phenomenon in which a bed of solid particles acquires a fluid like properties due to the interstitial upward flow of fluid (gas or liquid) through the bed [1]. Fluidized beds have been widely used in heat exchange processes because of their unique ability of rapid heat transfer and uniform temperature. Fluidized bed heat exchangers are employed to enhance heat transfer capacity in atmospheric and pressurized fluidized beds, such as in boilers and condensers of thermal power planets. Heat transfer from hot solids to the heat exchanger surfaces in the bed is achieved by using in-bed tubes [2]. The well-known theoretical models are classified as: The packet model proposed by Mickley et al in 1955 [3] who assumed that the surface is covered by packet of particles. Packet properties can be taken as that of bed at incipient condition and the old packet is frequently refreshed by a new one by means of the passing bubbles. The single particle model is another model, which had been suggested by Botterill et al in 1936 [4]. He considered a single particle near the transfer surface with a gas gap of one-fifth the particle diameter thickness as an aspirator. The new model is the surface particle emulsion model which was proposed by Li Wang et al in 2005 [5]. The model considers that the inhomogeneity of the emulsion packets is immediately adjacent to the heat transfer surface and discards the adjustable gas film between the immersed surface and emulsion. They concluded that the model showed improved description and quantitative prediction for local heat transfer coefficients around a horizontally immersed tube in a fluidized bed. Al Bajary [6] studied theoretical models of heat transfer between a shallow gas fluidized bed and the surface of a vertical tube immersed in it. The results obtained show that the heat transfer coefficient increases with the increase of the solid particle heat capacity, gas thermal conductivity and decreases with the increase in the solid particle diameter. Al-Saba'awi [7] presented a semi-empirical correlation to predict the average heat transfer coefficient between a shallow gas fluidized bed and a single immersed horizontal tube. He concluded that the model presented is valid for velocities four times higher than the minimum fluidizing velocity. Gao et al. [8] presented a computational simulation of gas flow and heat transfer near an immersed object in fluidized bed. The gas flow and heat transfer between fluidized bed and the surface of an immersed tube was numerically simulated based on a double particle layer and porous medium model. Natale, et al. [9] studied a single particle model for surface-to-bed heat transfer in fluidized bed. They presented a semi empirical single particle model for the description of heat transfer between a submerged surface and a fluidized bed. Xuejun Zhu, et al. [10] studied the local heat transfer mathematical model between a vibrated fluidized bed and a single horizontal immersed tube. Al Ali [11] studied experimentally the heat transfer from a plain horizontal tube of $12.5 \mathrm{~mm}$ diameter in shallow gas fluidized bed. Rasouli et al. [12] studied experimentally the effect of annular fins on heat transfer of a horizontal immersed tube in bubbling fluidized bed. Nima et al. [13] studied experimentally the influence of the axial position, particle diameter and the superficial gas velocity on the heat transfer coefficient from a small horizontal tube immersed in fluidized bed. In this study, heat transfer from horizontal tube immersed in a shallow gas fluidized bed with silica sand shall be investigated. The work is divided into two parts; theoretical in terms of proposing the model based on dividing the tube surface into three parts (bottom, side and top) and developing a formula that could be used as first approximation for design purposes, and experimental in terms of measuring particle residence time at the bottom portion of the tube surface, which is required to estimate the average heat transfer coefficient between shallow gas-solid fluidized bed and single immersed horizontal tube, and hence completing the model. Through an overall look at the literature review related to the fluidized beds, one can find that there are many papers dealing with the fluidization characteristics and bubble characteristics, heat transfer to immersed surfaces, 
theoretically or experimentally, but papers tackling heat transfer to horizontal tube by dividing its surface to the three sections (top, side and bottom) are very rare, until now.

\section{Experimental setup}

The experiments were carried out in a three dimensional fluidized bed with the cross section $(15 \times 15) \mathrm{cm}$ and height $40 \mathrm{~cm}$ was made from a commercial transparent acrylic plastic sheet. The thickness of the transparent sheet is $2.8 \mathrm{~mm}$. This transparency allowed the visual observation of the general circulation of the particle. The distributor plate was made of a $3 \mathrm{~cm}$ thickness of commercial sponge sandwiched by two sheets of very fine polyester fabric all over the bed bottom area. To ensure a uniform distribution of the fluidized gas, the fluidizing air was supplied by an air compressor and its flow was measured by a U-tube manometer and orifice meter. The solid particles used in this study were river sand with mean diameter $(0.23$, $0.36,0.51$ and 0.64$) \mathrm{mm}$ with properties listed in table (1). The heat transfer tubes used in this study were a solid shaft with diameters $(12.5,16,19$ and 25) mm located at $(65,52,39$ and 26) $\mathrm{mm}$ above the distributor plate. The minimum fluidizing velocity was calculated on the basis of Ergun equation for pressure drop in a packed bed [14] which at incipient fluidization is given by:

$$
\frac{\Delta \mathrm{P}_{m f}}{L}=\frac{150\left(1-\varepsilon_{m f}\right)^{2}}{\varepsilon_{m f}^{3}} \frac{\mu U_{m f}}{\left(\phi_{s} d_{p}\right)^{2}}+\frac{1.75\left(1-\varepsilon_{m f}\right)}{\varepsilon_{m f}^{3}} \frac{\rho_{f} U_{m f}^{2}}{\phi_{s} d_{p}}
$$

The above test rig used to measure the particle residence time and bubble fraction at the bottom side of the tube by using a digital camera with speed $30 \mathrm{fram} / \mathrm{s}$.

Table (1):physical property of fluidized particle

\begin{tabular}{|l|l|l|l|l|l|l|}
\hline Gauge & $\begin{array}{c}\mathrm{d}_{\mathrm{p}} \\
(\mathrm{mm})\end{array}$ & $\begin{array}{c}\rho_{s} \\
\left(\mathrm{~kg} / \mathrm{m}^{3}\right)\end{array}$ & $\begin{array}{c}\mathrm{C}_{\mathrm{s}} \\
(\mathrm{J} / \mathrm{kgK})\end{array}$ & $\varepsilon_{m f}$ & $\begin{array}{c}\mathrm{U}_{\mathrm{mf}} \\
(\mathrm{m} / \mathrm{sec})\end{array}$ & $\begin{array}{c}\mathrm{k}_{\mathrm{s}} \\
(\mathrm{W} / \mathrm{mK})\end{array}$ \\
\hline 70 & 0.23 & 2668 & 856 & 0.441 & 0.0685 & 68 \\
\hline 50 & 0.36 & 2631 & 856 & 0.415 & 0.0845 & 68 \\
\hline 40 & 0.51 & 2628 & 856 & 0.409 & 0.105 & 68 \\
\hline 30 & 0.64 & 2625 & 856 & 0.40 & 0.1381 & 68 \\
\hline
\end{tabular}

e.

\section{Models development}

In the present work the two models, namely the SPE and the single particle, were used. The tube is divided into three regions according to the motion of fluid around it. Therefore, the surface particle emulsion heat transfer model SPE is to be used for modeling the particle cap, and the single particle model for the side and bottom of the tube. The surface particle heat transfer model was newly introduced in the literature. When a fluidized bed is operated in the bubble regime, an immersed surface is covered by the bubble phase and the emulsion phase alternatively. Within a distance of one particle diameter, $d_{p}$, from the surface, the heat transfer is treated as through a dispersed particle touching the surface. When the distance from the surface is larger than $d_{p}$, the heat transfer is dealt with as through an emulsion phase with homogeneous properties. The following assumptions are considered:

1. The particles are uniform spheres.

2. The heat transfer process occurs in a direction perpendicular to the surface.

3. The fluidizing media is transparent to radiation and it dose not radiate itself.

4. The convective heat transfer is independed of the conductive and radiative heat transfer. 
5. The de-fluidized particle cap at the upper portion of the tube to be stagnant was considered. Fig. (1) Simulates the model.

The air gap thickness between the surface and the particle is assumed to be stagnant because it is very small, therefore conduction heat transfer is considered.

The conduction heat transfer between the emulsion and an immersed surface can be written as follows:

$$
\begin{aligned}
& \frac{\partial T}{\partial t}=\alpha_{g} \frac{\partial^{2} T_{g}}{\partial x^{2}} \\
& \frac{\partial T}{\partial t}=\alpha_{p} \frac{\partial^{2} T_{p}}{\partial x^{2}}
\end{aligned}
$$

The initial condition are:

$\mathrm{t}=0 \quad \mathrm{~T}=\mathrm{T}_{\mathrm{b}} \quad$ when $\mathrm{x}=0$

And the boundary condition will be:

$\mathrm{t} \geq 0 \quad \mathrm{~T}=\mathrm{T}_{\mathrm{s}} \quad$ when $\mathrm{x}=0$

$\mathrm{t} \geq 0 \quad \mathrm{~T}=\mathrm{T}_{\mathrm{b}} \quad$ when $\mathrm{x} \rightarrow \infty$

The convective heat transfer coefficient between the gas in the emulsion and an immersed surface is calculated from the correlation [15]

$h_{e c v}=0.12 \operatorname{Re}^{0.8} \operatorname{Pr}^{0.43} \frac{k_{g}}{d_{p}} \frac{\left(1-\varepsilon_{f}\right)^{0.133}}{\varepsilon_{f}^{0.8}}$

Where $\varepsilon_{f}=\frac{1}{2.1}\left\{0.4+\left[\frac{200 \mu_{g} U_{f}}{d_{p}^{2}\left(\rho_{p}-\rho_{g}\right) g}\right]^{1 / 3}\right\}$

It is now clear that the single particle model will be used for the side and bottom of the tube, which had been verified by Al-Bajary [6] and Al-Sabawi [7]. Then the assumptions are as follows:

1. Sphericity of particle is unity.

2. Thermal and physical properties of particles and gas are constant.

3. Radiation effect can be neglected.

4. Contact resistance is neglected.

5. The particle has low Biot number $(\mathrm{Bi}<0.1)$.

6. Any particle at the main body of the bed is at bed temperature. At the transfer surface, particle starts to be heated or cooled by the fluid which has the same surface temperature by convection.

7. Heat transfer by convection between the interstitial gas and immersed surface can be neglected.

The derivation of the mathematical model depends on the law of energy conservation so we have

$-h_{c} A_{s}\left(T-T_{s}\right)=\rho_{s} c_{s} V_{s} \frac{d T}{d t}$

The heat transfer equation is

$Q_{(t)}=h_{c} A_{s}\left(T-T_{s}\right)$ 
Since the particle is in contact with the transfer surface, the fluid velocity is going to be zero, so the experimental value of Nusselt number defined by Karamers [17] between the particle and the surrounded gas is going to be adopted which is (3.2), so

$$
N u_{c}=\frac{h_{c} d_{p}}{k_{g}}=3.2
$$

By substituting equation(5) after integration and separation the variables with equation(7) in equation(6) we get

$$
Q_{(t)}=3.2 \times 2 \pi \times k_{g} R_{p}\left(T_{b}-T_{s}\right) e^{-z t}
$$

Where: $z=\frac{h_{c} A_{s}}{\rho_{s} c_{s} V_{s}}$

The distribution of particle residence time was a statistical case and has random shape. However, authors agree that any random event, relative to the time, could be exponentially distributed. Exponential Distribution provides probabilities for the amount of time/space between successive events, so the general shape of gamma distribution function(GDF) is [18]:

$$
f(t)=\frac{\lambda(\lambda t)^{\alpha-1}}{\Gamma(\alpha)} e^{-\lambda t} \quad t<0
$$

The exponential distribution function(EDF) is a special case of what is so called gamma distribution function(GDF). By setting $\alpha$ to 1 , the gamma formula is then:

$$
f(t)=\lambda e^{-\lambda t} \quad \text { where } \lambda=\frac{1}{\beta} \quad \text { (10) Physically, }
$$

$\beta$ is the average time of event occurrence, $(\mathrm{t})$ is a time that produces $\beta$. Then $\beta$ is going to be replaced by the term (tr) which is the average particle residence time, so:

$$
f(t)=\frac{1}{t r} e^{-t / t r}
$$

The heat transfer equation, for particle in contact with the surface, the absorbed or given heat is:

$\bar{Q}=\int_{0}^{\infty} Q(t) f(t) d t$

By substituting equation (8)and equation (11) into the equation (12) and integrating it, for each particle we can get:

$$
\bar{Q}=6.4 \pi R_{p} k_{g}\left(T_{b}-T_{s}\right) \frac{1}{(1+z t r)}
$$

For generalizing this equation for the whole surface, it would then be necessary to estimate the particle concentration at the surface, i.e. particle/unit area. Ziegler [19] assumed that the particle distribution at the surface is hexagonal, i.e.: $N_{p}=\frac{1}{2 R_{p}^{2} \sqrt{3}}$

Multiplying the number of particles per unit $\operatorname{area}\left(\mathrm{N}_{\mathrm{p}}\right)$, by the amount of heat that can be transferred by single particle, $(\bar{Q})$, gives the heat transfer per unit area for the immersed surface, or: 
$\bar{Q} N_{p}=h_{o}\left(T_{b}-T_{s}\right)$

But: $N u=\frac{h_{o} d_{p}}{k_{g}}$

$$
N u=\frac{6.4 \pi / \sqrt{3}}{\left[1+\frac{4.8 \operatorname{tr} k_{g}}{\rho_{s} c_{s} R_{p}^{2}}\right]}
$$

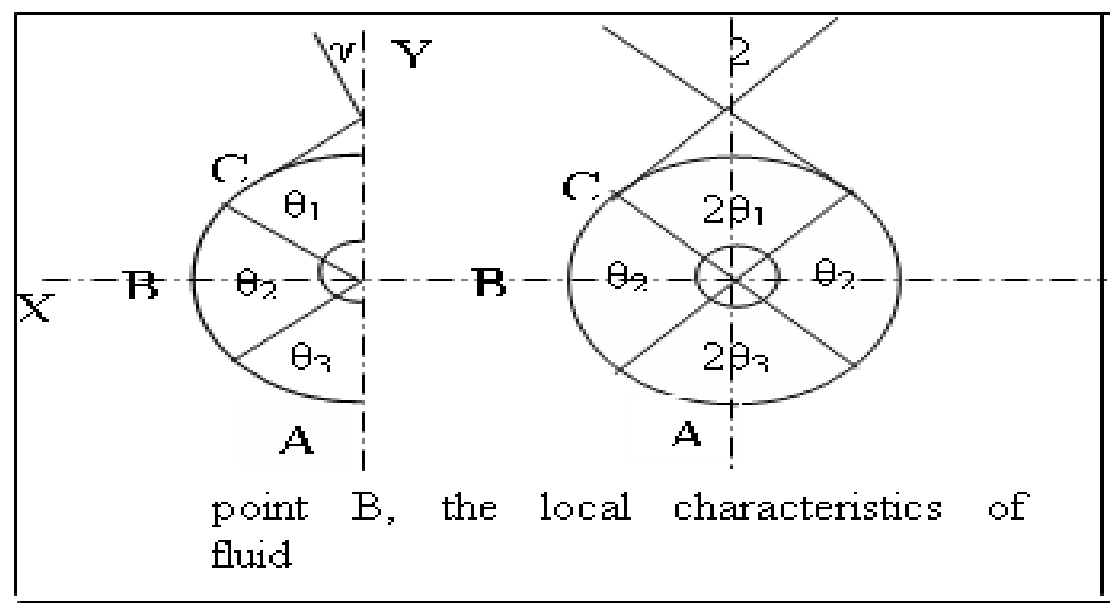

fig.(1): simulation of heat transfer models.

\section{Particle Residence Time (tr)}

Since the heat transfer mechanism depends on the transient heat transfer during a residences time, the thermal properties of the materials and the residence time itself are important factors affecting heat transfer.

There is some discrepancy in the values for residence time given in the literature. For example, the values obtained by Baskakove et al [20] and Vedamurthy and Sastri, are much lower than those obtained by Mickley and Williams [3] and Broghton. However, since Mickley and Williams give greater details of their experimental procedure, and their results agree well with those of Broughten, it was decided to use those results. These results are correlated by the following equation :

$$
t r_{1}=8.932\left[\frac{1}{(N-1)^{2}}\right]^{0.2}\left[\frac{d_{p} g}{U_{m f}^{2}}\right]^{0.0765}\left[\frac{d_{p}}{D_{t}}\right]^{0.5}
$$

This correlation is used for the side section of the tube. For the bottom section of the tube the residence time $\left(\operatorname{tr}_{2}\right)$ is obtained from experimental work.

\section{Bubble Fraction $\left(\mathbf{f}_{\mathbf{0}}\right)$}

The bubble fraction of the heat transfer surface area exposed to bubble is also important to the heat transfer surface. This can be found by experimental measurements of the bed depth since:

$$
f_{o}=1-\frac{H_{m f}}{H_{f}}
$$


As started by Gelperin and Einstein [21], some experimental measurements have been done to connect the bubble fraction with the fluidizing parameter and the results are given by:

Main $f_{o 1}=0.08553(N-1)^{0.21}\left[\frac{U_{m f}^{2}}{d_{p} g}\right]^{0.1948}$

This equation is used for the side section and the bottom section of the tube. The bubble fraction $\left(f_{o 2}\right)$ is obtained from the experimental work.

\section{Determination of Heat Transfer Coefficient}

The local heat transfer coefficient was determined at three sections and then its average was taken. The local heat transfer coefficient at the top section of the tube was determined by using the SPE model, by taking the summation of conduction and convection heat transfer coefficient. The local heat transfer coefficient for the side and bottom sections of the tube was determined as follows:

$$
h_{o}=\frac{6.4 \pi / \sqrt{3}}{\left[1+\frac{4.8 \operatorname{tr} k_{g}}{\rho_{s} c_{s} R_{p}^{2}}\right]} \frac{k_{g}}{d_{p}}
$$

When the side and bottom sections of the tube are exposed to bubble fraction, the heat transfer by convection between the interstitial gas and the immersed surface was assumed to be neglected, so the final equation for calculating the local heat transfer coefficient at side sections becomes as follows:

$h_{L}=h_{o}\left(1-f_{o 1}\right)$

And that for bottom section as follows:

$h_{L}=h_{o}\left(1-f_{o 2}\right)$

Finally, the average heat transfer coefficient for the three parts of the tube can be found as follows:

$h_{a v}=\frac{\int h_{L} d A}{A}$

Or

$h_{a v}=\frac{\sum h_{l} \times R_{t} \times \theta}{\pi \times R_{t}}$

Where $\theta$ : angle of three section of the tube.

\section{Results and Discussion}

\section{Effect of Fluidizing Velocity on Particle Residence Time}

Figures (2) to (5) show the variation of particle residence time with fluidizing velocity for different particle size, tube size and tube position. It was noted that the particle residence time decreases with an increase in fluidizing velocity, and that is because the bubble frequency increases with an increase in fluidizing velocity. 
Each group of these figures are plotted for a different tube size at a different particle size and tube position, and shows that there is a little effect of tube size on particle residence time, but particle residence time increases when particle diameter increases, and when tube position decreases particle residence time decreases.

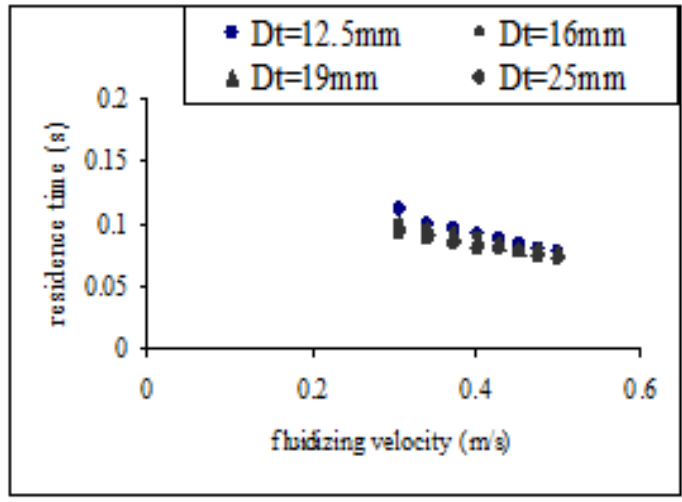

Fig.(2):variation of particle residence time with fluidizing velocity at different tube sizes and $(\mathrm{dp}=0.23 \mathrm{~mm}$, position $=65 \mathrm{~mm})$.

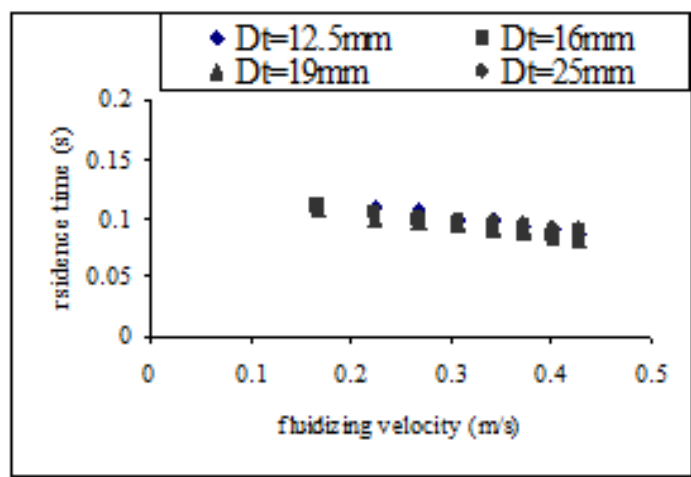

Fig.(4):variation of particle residence time with fluidizing velocity at different tube sizes

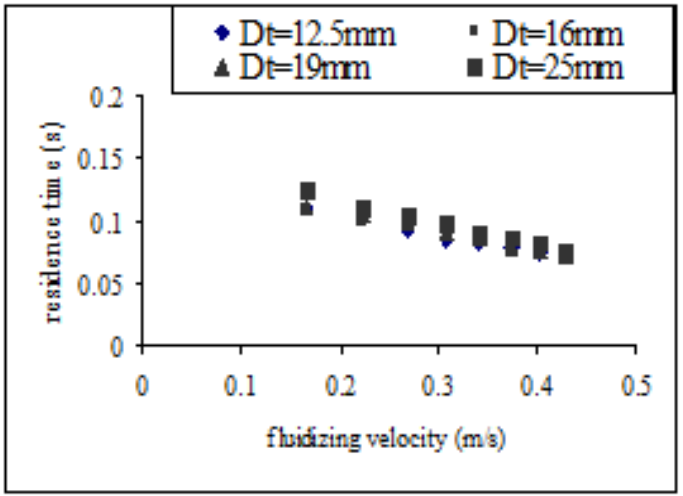

Fig.(3):variation of particle residence time with fluidizing velocity at different tube sizes and $(\mathrm{dp}=0.36 \mathrm{~mm}$, position $=52 \mathrm{~mm})$.

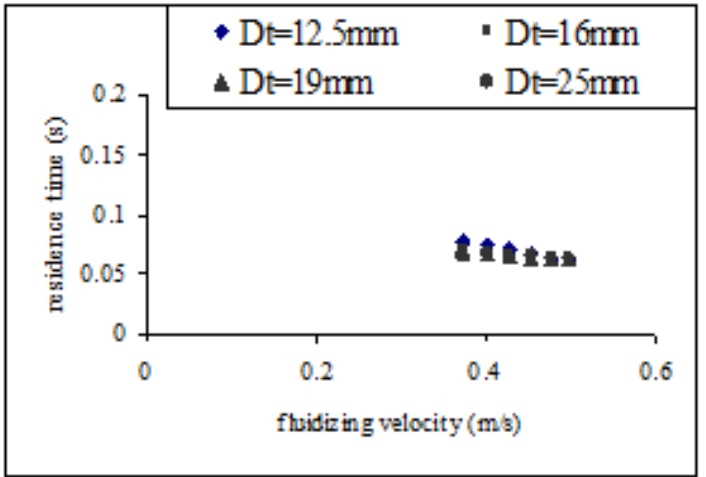

Fig.(5):variation of particle residence time with fluidizing velocity at different tube sizes and

\section{Effect of Particle Diameter on Average Heat transfer Coefficient}

The effect of particle diameter on average heat transfer coefficient with respect to the fluidizing velocity for different tube positions and sizes is presented in figs.(7)to(10).

From these figures, it can be noticed that the average heat transfer coefficient decreases with an increase in particle diameter, and such behavior may be explained as follows: the net surface area of the particle in contact with the tube immersed in fluidized bed is higher for the small particles than the large particles, and another explanation could be the residence time measurements, figures (3) to (6). Small particles $(0.23 \mathrm{~mm})$ have shorter residence time on the transfer surface so their heat transfer coefficient will increase. This results was in good agreement with Al-Ali [11], Nima et al.[13] and Li Wang et al.[5].

\section{Effect of Tube Position on Average Heat Transfer Coefficient}

The results in figures (11) to (14) show the influence of tube position on average heat transfer coefficient with respect to fluidizing velocity for different particle sizes and tube sizes. It is noticeable that the average heat transfer coefficient increases with the increase in the elevation of the tube from the distributor plate. This is due to the fact that at low 

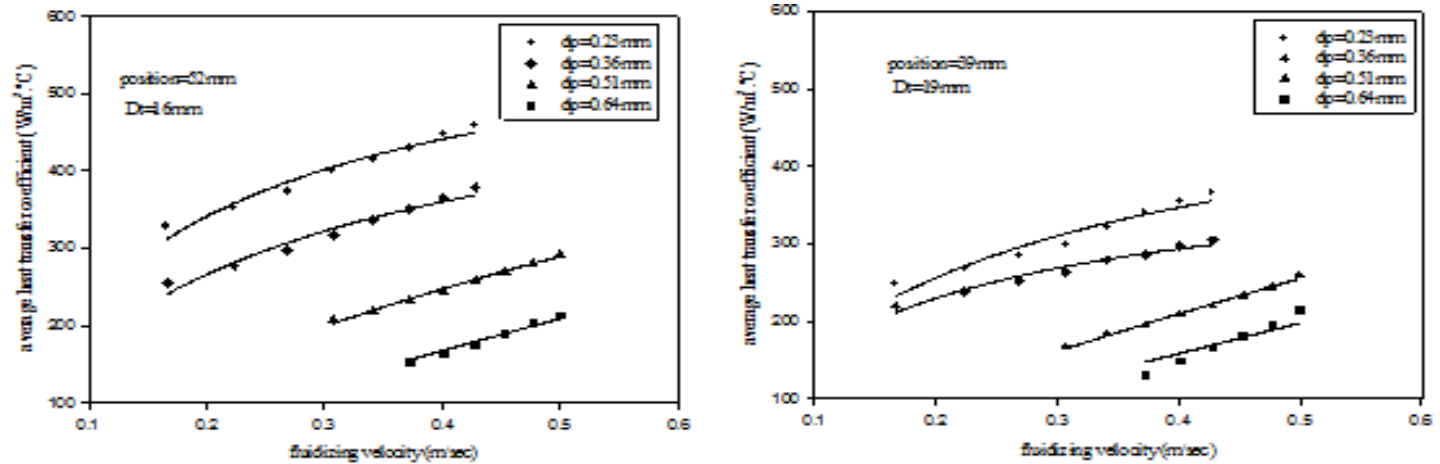

fig(7) variation of average heat tansfer coefficient with fhidi zing velocity at a

fig (8). variation of average hmt transfer coefficient with fhidiving velocity at a different particle diameter and ( $\mathrm{d}=19 \mathrm{~mm}$, position=39men)
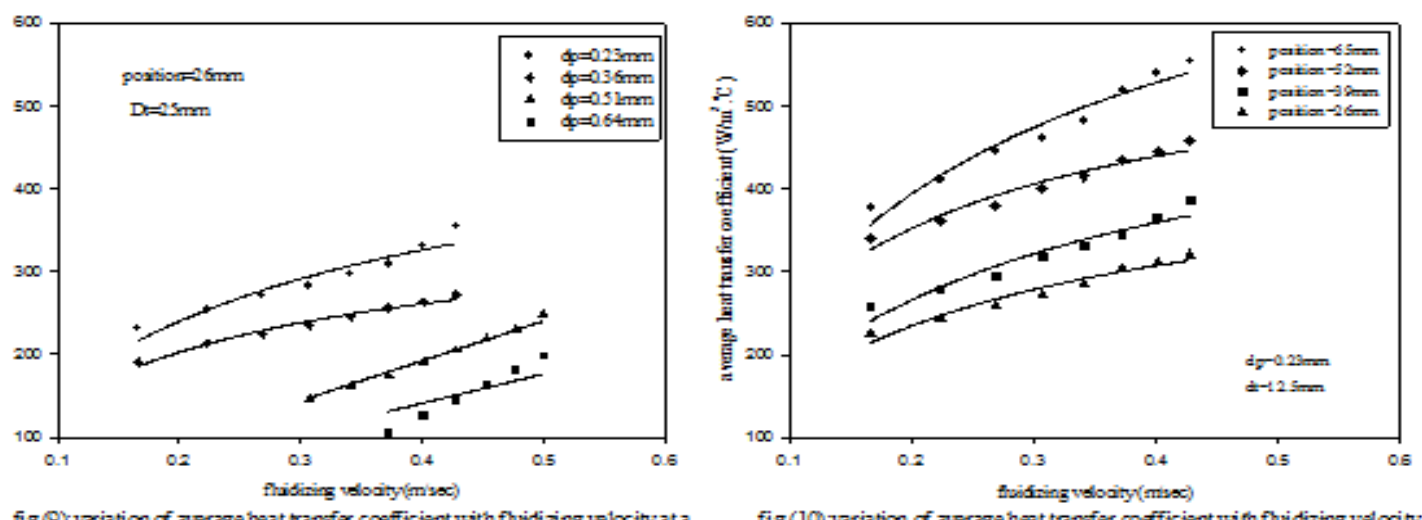

fig (9) variation of average heat transfer coefficient with fhuidizing velocity at a differint particle diameter and ( $d=25 \mathrm{~mm}$,position $=26$ men).

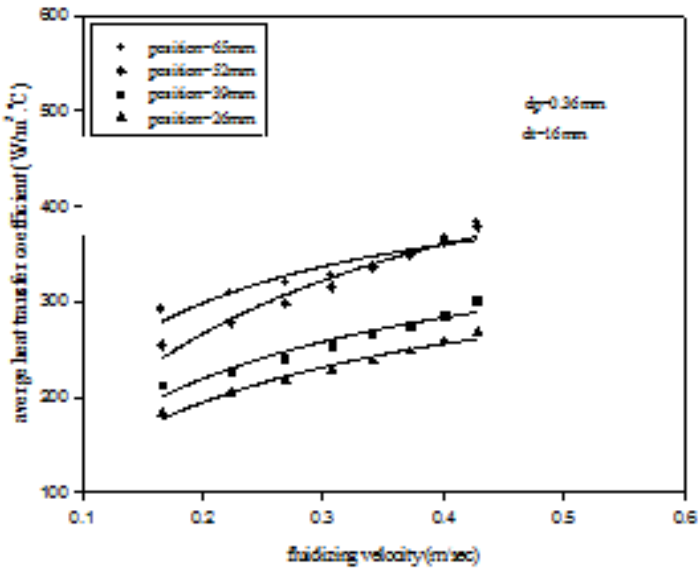

fig (11).variation of average heat transer coefficient with fhuidizing velocity at adifferent tibe position and ( $d \mathrm{~s}=0.36 \mathrm{~mm}, \mathrm{~d}=16 \mathrm{mem}$ ).

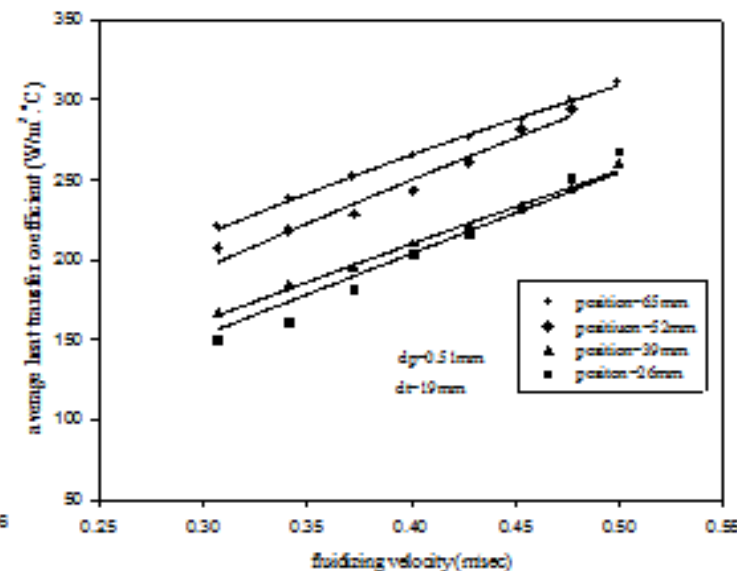

fig (12).vriation of average heat transfer coefficient with fluidizing velocity at a different the position and ( $\phi=0.5 \mathrm{lmm}, \mathrm{d}=19 \mathrm{~mm}$ )

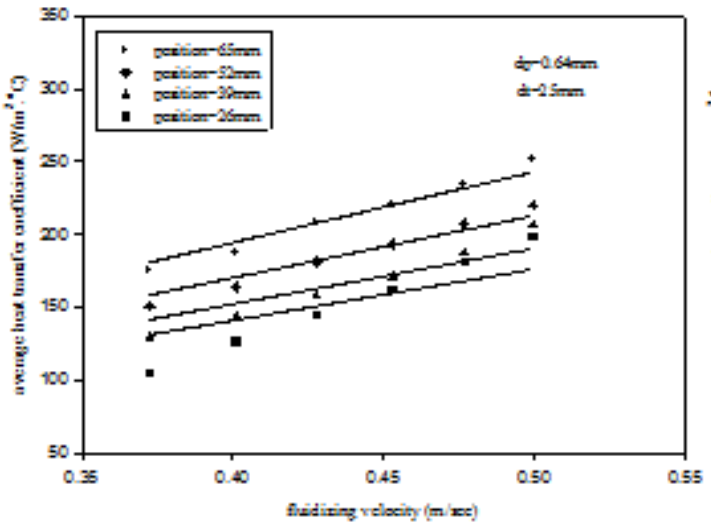

fiz (13) variation of aversyo hest tannfer wofficiont with fluidizing volocity a a different tobeposi sion and (dp=0.64mmd: $=25 \mathrm{~mm})$.

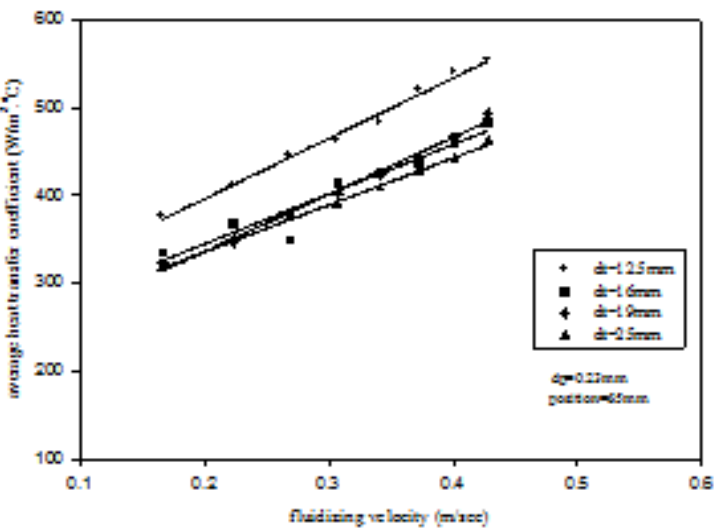

fig (14) variation of average heat transer coefficient with fhidizing velocitya a differen tube size and (dp=0.27m, position=65mm) 
fluidizing velocity, bubbles are infrequent so that particles tend to have a long residence time at the heat transfer surface, leading to low heat transfer coefficient. This is particularly true at low position of the bed where the bubbles are small and can easily miss the heat transfer tube. At higher flow rates, coalescence gives larger bubbles which tend to cause a higher frequency of particle replacement so that the particle residence time is short and leads to high heat transfer coefficient at higher position of the tube within the bed.

\section{Effect of Fluidizing Velocity on Average Heat Transfer Coefficient}

The effect of fluidizing velocity on the average heat transfer coefficient can be seen in figures (11) to (14) for different tube positions at different particle sizes and tube sizes. The figures show that the average heat transfer coefficient increases with the increase in fluidizing velocity. It can be concluded that the heat transfer rate between the tube and the fluidized bed depends on the particle concentration close to the heat transfer surface and particle residence time at the tube surface [4]. From figures (3) to (6) it can be seen that the particle residence time decreases with the increase in fluidizing velocity so that at low velocity the average heat transfer coefficient decreases. The large values of average heat transfer coefficient could be obtained with short residence time of particles at higher velocity of fluidization. The particle residence time on the tube surface depends on the replacement rate of the particles by bubbles. Thus, the initial increase in average heat transfer coefficient with fluidizing velocity is due to the reduction in particle residence time.

\section{Effect of Tube Size on The Average Heat Transfer Coefficient}

Figures (15) to (18) show the effect of tube size on the average heat transfer coefficient for different particle sizes and tube positions. Figures (16) to (18) show that there is no large effect on average heat transfer coefficient when the tube size is changed and the results agree with Al-Sabawi [7]. Figure (15) shows the effect of four tube sizes for a particle diameter equal to $(0.23 \mathrm{~mm})$ and tube position equal to65mm above the distributor plate. It was noted that the average heat transfer coefficient increases for tube diameter equal to $12.5 \mathrm{~mm}$. This can be explained: as the particle diameter decreases and the tube size decreases the angle of repose of particle for the cap of defluidized particle decreases at the top surface of the tube and at small particle the residence time at the side and bottom section of the tube decreases due to the increases in fluidizing velocity leading to an increase in the average heat transfer coefficient around the tube.

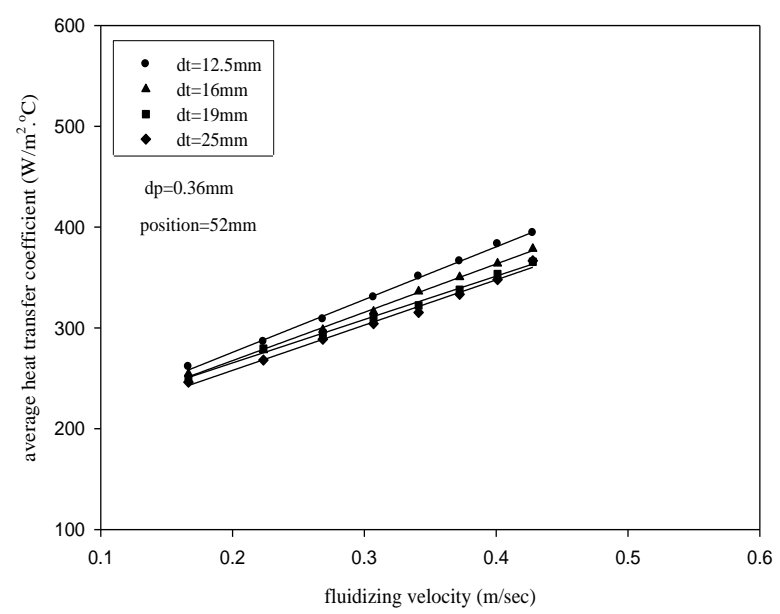

fig.(15):variation of average heat transfer coefficient with fluidizing velocity a a differen tube size and $(\mathrm{dp}=0.36 \mathrm{~mm}$, position $=52 \mathrm{~mm})$.

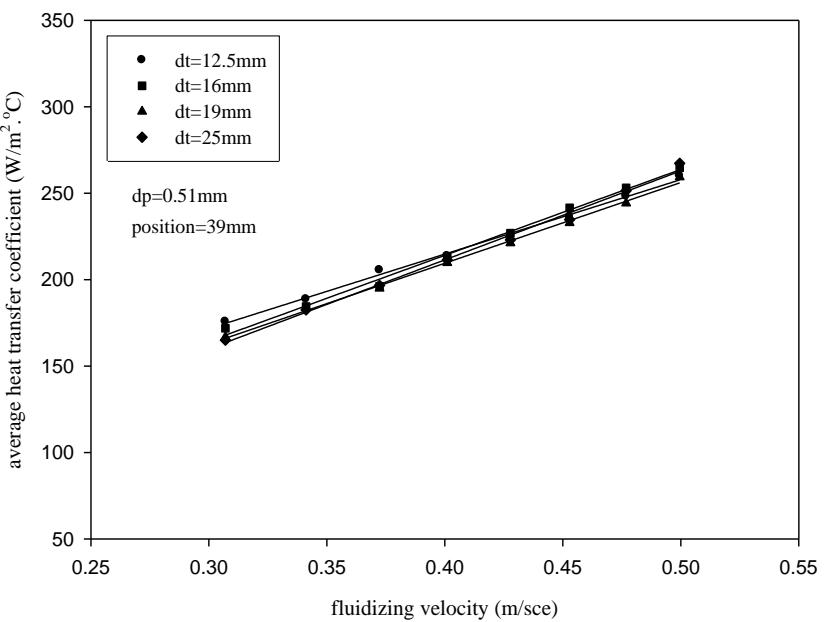

fig.(16):variation of average heat transfer coefficient with fluidizing velocity at a differen tube size and $(\mathrm{dp}=0.51 \mathrm{~mm}$,position $=39 \mathrm{~mm})$. 


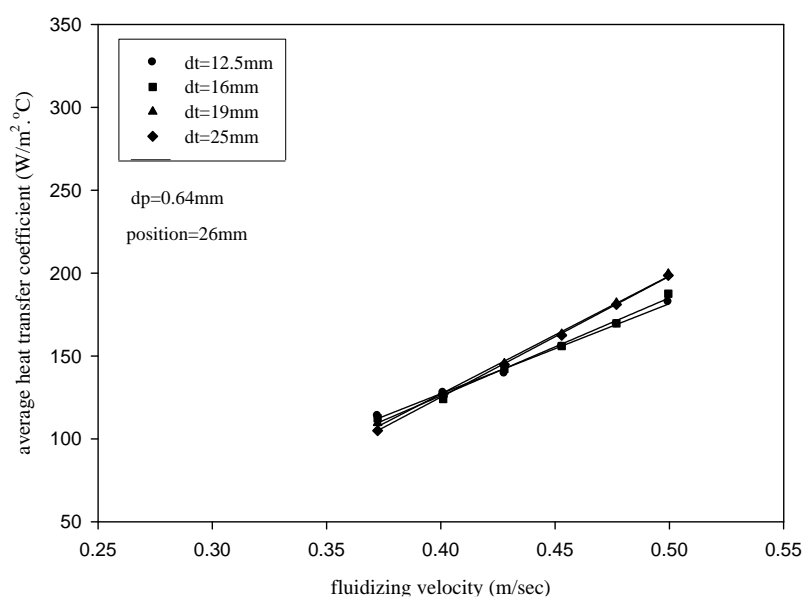

Fig. (17) variation of average heat transfer coefficient with fluidizing velocity at a different tube size and $(\mathrm{dp}=0.64 \mathrm{~mm}$. position $=26 \mathrm{~mm})$

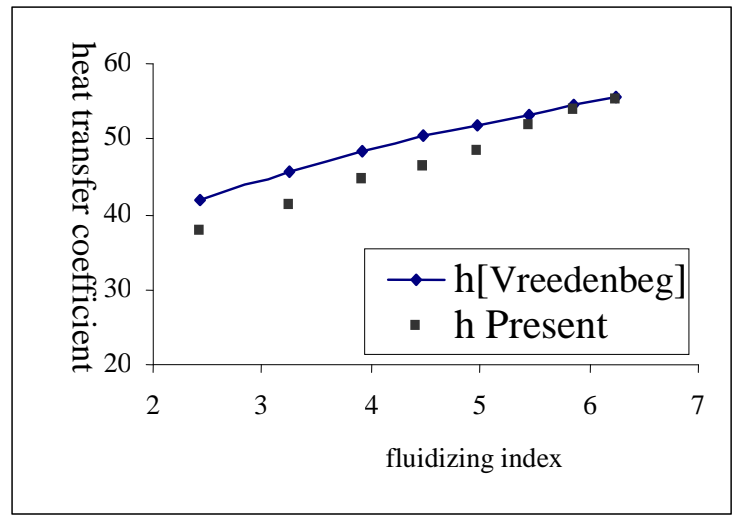

Fig.(18):comparision of the present work with experimental Corrolation at $(\mathrm{d} p=0.23 \mathrm{~mm}$, $\mathrm{dt}=12.5 \mathrm{~mm}$ and position $=65 \mathrm{~mm})$.

\section{Comparison With Experimental Data}

One of the most important objectives of the current study is to estimate the average heat transfer coefficient around a horizontal tube immersed in a shallow gas fluidized bed by developing an empirical formula that could be used as first approximation for design purposes. After using two different models: the surface particle emulsion heat transfer model and the single particle model for estimating the average heat transfer coefficient, a comparison with experimental correlations was made. These models are valid in the solid particle ranging between (0.23-0.64)mm. Figures (19) and (20) compare calculated results from the present model with experimental correlation from Vreedenbverg [22]. Vreedenberg measured the heat transfer coefficient on a single water cooled horizontal tube immersed in a shallow fluidized bed. Different tube sizes, particle sizes, shapes and densities were used. The comparison was made at position $65 \mathrm{~mm}$ above the distributor plate and $0.23 \mathrm{~mm}$ particle diameter with different tube sizes. It can be noted that the calculated results agree reasonably well with the experimental data, with some deviation and that is because of different measuring techniques used in each study. Another comparison was made with Al-Ali [11] and Rasouli [12]. Al-Ali used a single horizontal tube of diameter $12.5 \mathrm{~mm}$ immersed in a shallow fluidized bed with particle diameter equal to $0.253 \mathrm{~mm}$. Rasouli also used single horizontal tube of $15 \mathrm{~mm}$ diameter immersed in a cold bubbling fluidized bed with fluidized particle of silica sand of mean diameter $(0.2$ and 0.307$) \mathrm{mm}$. Figures (21) to (24) show that comparison. This comparison was made at a position of $52 \mathrm{~mm}$ and particle diameter $0.23 \mathrm{~mm}$ with different tube sizes. It is clear that the calculated results from the SPE model and single particle model agree well with experimental data. Also, another comparison was made with Al-Ali [11], Zabrodesky [23], Grewal [24] and Chen [25] for maximum heat transfer coefficient. Figure (25) show that comparison for tube diameter $12.5 \mathrm{~mm}$ and $65 \mathrm{~mm}$ position above the distributor plate at a different particle diameter. A good agreement for maximum heat transfer coefficient from the present work with experimental correlations were noted, except for particle diameter equal to $0.23 \mathrm{~mm}$ where the value of the heat transfer coefficient was higher than that of experimental value, and that is because the small particle in shallow fluidized bed will have high value of bubble frequency, so the particle residence time will decrease and as a result heat transfer coefficient will increase. 


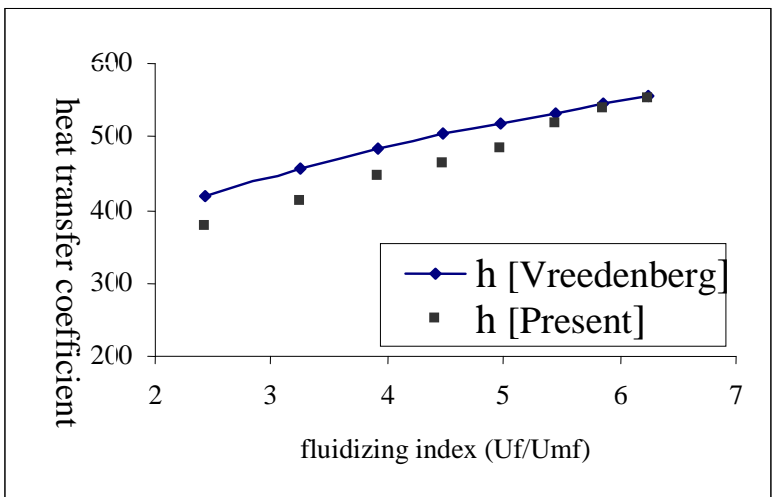

Fig.(19):comparision of the present work with experimental Corrolation at $(\mathrm{dp}=0.23 \mathrm{~mm}, \mathrm{dt}=16 \mathrm{~mm}$ and position $=65 \mathrm{~mm}$ ).

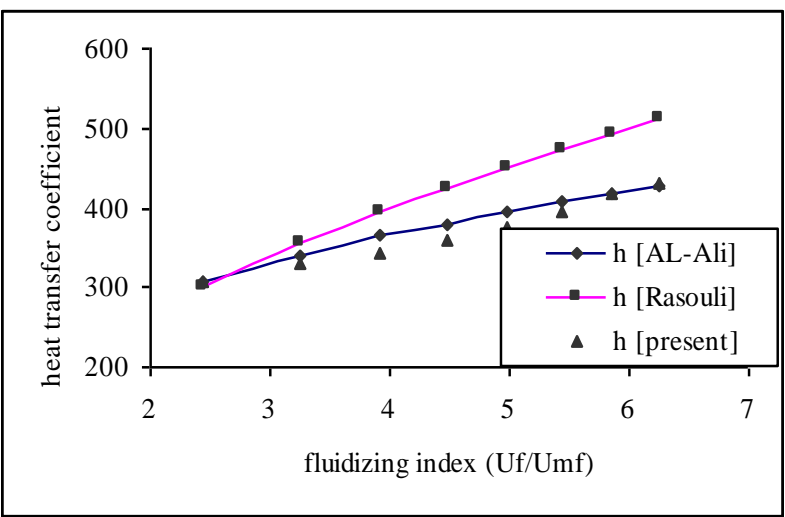

Fig.(21):comparision of the present work with experimental Correlation at $(\mathrm{dp}=0.23 \mathrm{~mm}, \mathrm{dt}=25 \mathrm{~mm}$ and position $=65 \mathrm{~mm}$ ).

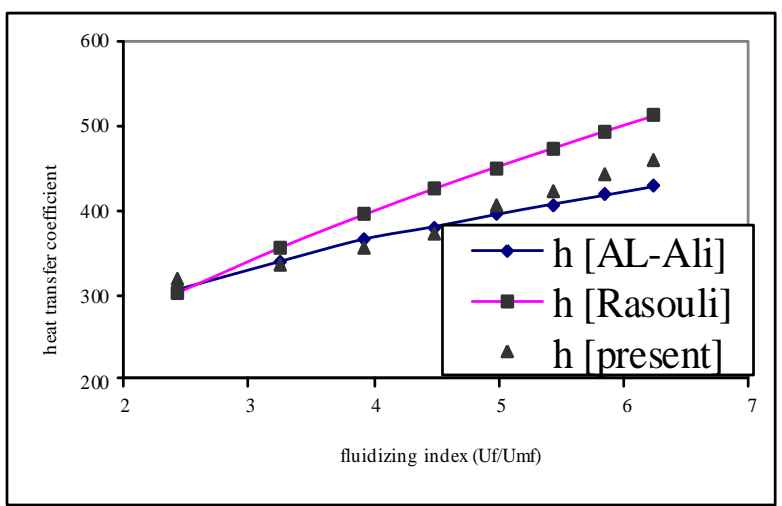

Fig.(23):comparision of the present work with experimental correlation at $(\mathrm{dp}=0.23 \mathrm{~mm}, \mathrm{dt}=25 \mathrm{~mm}$ and position $=52 \mathrm{~mm}$ ).

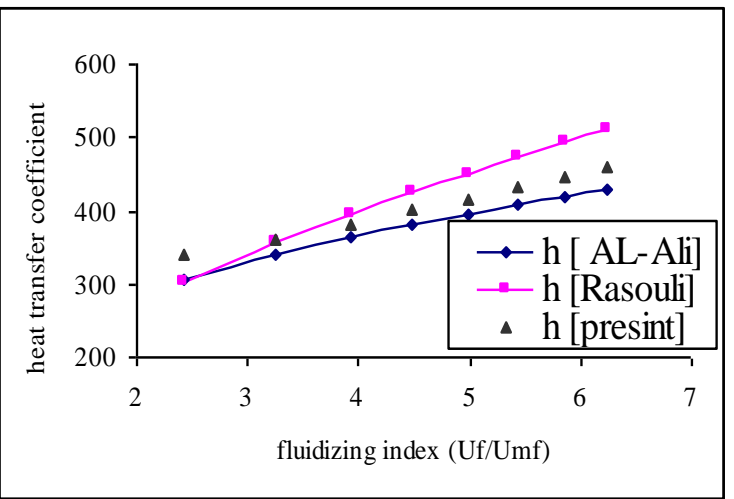

Fig.(20):comparision of the present work with experimental Correlation at $(\mathrm{dp}=0.23 \mathrm{~mm}$, $\mathrm{dt}=19 \mathrm{~mm}$ and position $=65 \mathrm{~mm})$.



Fig.(22):comparision of the present work with experimental correlation at

$(\mathrm{dp}=0.23 \mathrm{~mm}, \mathrm{dt}=19 \mathrm{~mm}$ and position $=52 \mathrm{~mm})$.

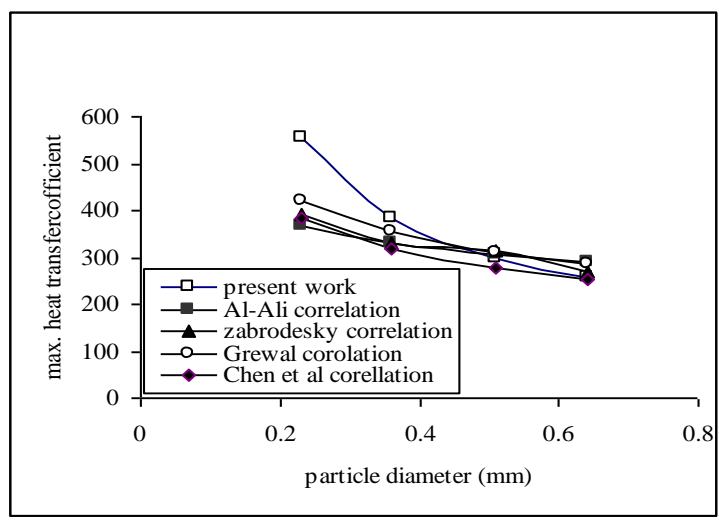

Fig.(24):comparision the present work with experimental correlationfor maximum heat transfer coefficient at $(\mathrm{dt}=12.5 \mathrm{~mm})$. 


\section{Conclusions}

1. Particle size has a significant effect on the average heat transfer coefficient, where the fine particles have a higher heat transfer coefficient.

2. The average heat transfer coefficient was the highest with tube position in the upper position of the bed (in the lean phase).

3. The tube size has a little influence on the average heat transfer coefficient.

4. The average heat transfer coefficient increases with the increase in fluidizing velocity for all particle sizes used in the current study.

5. The cap of defluidized particles on the upper section of the tube reduces the heat transfer coefficient depending on the height of the cap, and that height depends on the tube size and position within the bed.

6. Particle residence time decreases with the increase in fluidizing velocity and decreases with the position near the distributor plate. But the size of the tube has a little effect on the particle residence time.

7. Bubble fraction has a significant effect on the local heat transfer coefficient in the side and bottom sections of the tube. Also, the value of bubble fraction decreases with the increase in fluidizing velocity.

8. The model used is valid in the particle size range between $(0.23-0.64) \mathrm{mm}$. The calculated results agree reasonably well with the experimental data obtained from the literature.

\section{Nomenclature}

\begin{tabular}{|c|c|c|}
\hline Symbols & Description & Unit \\
\hline $\mathrm{A}_{\mathrm{s}}$ & Surface area. & $\mathrm{m}^{2}$ \\
\hline $\mathrm{Cs}$ & Sand particle specific heat. & $\mathrm{kJ} / \mathrm{kg} .{ }^{\circ} \mathrm{c}$ \\
\hline $\mathrm{dp}$ & Particle diameter. & $\mathrm{m}$ \\
\hline $\mathrm{Dt}$ & Tube diameter. & $\mathrm{m}$ \\
\hline$f_{o}$ & $\begin{array}{l}\text { Time fraction of surface shrouded } \\
\text { by bubble(bubble fraction). }\end{array}$ & \\
\hline $\mathrm{g}$ & Gravity acceleration velocity. & $\mathrm{m} / \mathrm{s}^{2}$ \\
\hline $\mathrm{h}_{\mathrm{av}}$ & Average heat transfer coefficient. & $\mathrm{W} / \mathrm{m}^{2} \cdot{ }^{\circ} \mathrm{C}$ \\
\hline $\mathrm{h}_{\mathrm{ecd}}$ & $\begin{array}{l}\text { Conduction heat transfer coefficient } \\
\text { due to emulsion phase. }\end{array}$ & $\mathrm{W} / \mathrm{m}^{2} .{ }^{\circ} \mathrm{C}$ \\
\hline$h_{\text {ecv }}$ & $\begin{array}{l}\text { Convection heat transfer coefficient } \\
\text { due to emulsion phase. }\end{array}$ & $\mathrm{W} / \mathrm{m}^{2} \cdot{ }^{\circ} \mathrm{C}$ \\
\hline$h_{\text {er }}$ & $\begin{array}{l}\text { Radiation heat transfer coefficient } \\
\text { due to the emulsion phase. }\end{array}$ & $\mathrm{W} / \mathrm{m}^{2} .{ }^{\circ} \mathrm{C}$ \\
\hline$h_{b c v}$ & $\begin{array}{l}\text { Convection heat transfer coefficient } \\
\text { due to the bubble phase. }\end{array}$ & $\mathrm{W} / \mathrm{m}^{2} .{ }^{\circ} \mathrm{C}$ \\
\hline$h_{b r}$ & $\begin{array}{l}\text { Radiation heat transfer coefficient } \\
\text { due to the bubble phase. }\end{array}$ & $\mathrm{W} / \mathrm{m}^{2} .{ }^{\circ} \mathrm{C}$ \\
\hline $\begin{array}{l}\mathrm{h}_{1} \\
\mathrm{~h}_{\max }\end{array}$ & $\begin{array}{l}\text { Local heat transfer coefficient. } \\
\text { maximum heat transfer coefficient. }\end{array}$ & $\begin{array}{l}\mathrm{W} / \mathrm{m}^{2} \cdot{ }^{\circ} \mathrm{C} \\
\mathrm{W} / \mathrm{m}^{2} \cdot{ }^{\circ} \mathrm{C}\end{array}$ \\
\hline$h_{b}$ & Bubble heat transfer coefficient. & $\mathrm{W} / \mathrm{m}^{2} \cdot{ }^{\circ} \mathrm{C}$ \\
\hline $\mathrm{h}_{\mathrm{cd}}$ & Conduction heat transfer coefficient. & $\mathrm{W} / \mathrm{m}^{2}{ }^{\circ} \mathrm{C}$ \\
\hline $\mathrm{h}_{\mathrm{cv}}$ & Convection heat transfer coefficient. & $\mathrm{W} / \mathrm{m}^{2} \cdot{ }^{\circ} \mathrm{C}$ \\
\hline $\mathrm{h}_{\mathrm{e}}$ & Emulsion heat transfer coefficient. & $\mathrm{W} / \mathrm{m}^{2} \cdot{ }^{\circ} \mathrm{C}$ \\
\hline $\mathrm{h}_{\mathrm{r}}$ & Radiation heat transfer coefficient. & $\mathrm{W} / \mathrm{m}^{2} \cdot{ }^{\circ} \mathrm{C}$ \\
\hline $\mathrm{h}_{\text {total }}$ & Total heat transfer coefficient. & $\mathrm{W} / \mathrm{m}^{2} \cdot{ }^{\circ} \mathrm{C}$ \\
\hline
\end{tabular}




$\begin{array}{lll}\mathrm{K}_{\mathrm{g}} & \text { Gas thermal conductivity. } & \mathrm{W} / \mathrm{m} .{ }^{\circ} \mathrm{C} \\ \mathrm{L} & \text { Bed static depth. } & \mathrm{m} \\ \mathrm{N}_{\mathrm{p}} & \text { Number of particle per unit area. } & \mathrm{particle} / \mathrm{m}^{2} \\ \mathrm{Q}_{(\mathrm{t})} & \text { Heat transfer rate due to one particle } & \mathrm{W} \\ \bar{Q}(t) & \text { Time average heat transfer rate. } & \mathrm{W} \\ \mathrm{R}_{\mathrm{p}} & \text { particle radius. } & \mathrm{m} \\ \mathrm{R} & \text { Tube riduse. } & \mathrm{m} \\ \mathrm{T}_{\mathrm{a}} & \text { Air temperature. } & \mathrm{K} \\ \mathrm{T}_{\mathrm{b}} & \text { Bed temperature. } & \mathrm{K} \\ \mathrm{T}_{\mathrm{g}} & \text { gas temperature. } & \mathrm{K} \\ \mathrm{T}_{\mathrm{p}} & \text { particle temperature. } & \mathrm{K} \\ \mathrm{T}_{\mathrm{s}} & \text { Surface temperature. } & \mathrm{K} \\ \mathrm{t}_{\mathrm{r}} & \text { Particle residence time. } & \mathrm{s} \\ \mathrm{U}_{\mathrm{f}} & \text { Superficial fluidizing velocity. } & \mathrm{m} / \mathrm{s} \\ \mathrm{U}_{\mathrm{mf}} & \text { Minimum fluidizing velocity. } & \mathrm{m} / \mathrm{s} \\ \mathrm{V}_{\mathrm{s}} & \text { particle volume. } & \mathrm{m}\end{array}$

Greek Symbols

Symbol

Description

Unit

$\alpha \quad$ Shape factor of Gamma distribution function

$\alpha_{\mathrm{g}} \quad$ Thermal diffusivity of the gas.

$\alpha_{\mathrm{p}} \quad$ Thermal diffusivity of the particle.

$\mathrm{m}^{2} / \mathrm{s}$

$\beta$

Average particle residence time.

$\mathrm{m}^{2} / \mathrm{s}$

$\delta_{\mathrm{g}}$

Gas gap.

$\mathrm{s}$

particle gap.

$\mathrm{m}$

$\delta_{\mathrm{p}}$

$\Delta \mathrm{p}$

pressure drop across the bed.

$\mathrm{m}$

$\varepsilon_{\mathrm{f}} \quad$ Voidage

$\varepsilon_{\mathrm{mf}} \quad$ Bed voidage at minimum fluidizing velocity.

$\theta \quad$ Angle.

$\mu_{\mathrm{f}} \quad$ Viscosity of air.

$\varphi_{\mathrm{s}} \quad$ Solid sphericity.

$\lambda \quad$ Failure rate.

$\rho_{\mathrm{g}} \quad$ density of gas.

$\rho_{\mathrm{s}} \quad$ density of solid.

$\mathrm{N} / \mathrm{m}^{2}$

Subscripts

Symbol

description

Dimensionless Groups

$\begin{array}{llrl}\mathrm{a} & \text { atmospheric air. } & \mathrm{Bi} & \text { Biot number. }\left(\mathrm{h}_{\mathrm{c}} \cdot \mathrm{dp} / \mathrm{k}_{\mathrm{g}}\right) \\ \mathrm{b} & \text { bubble phase. } & \mathrm{N} & \begin{array}{c}\text { Fluidizing index. }(\mathrm{Uf} / \mathrm{Umf}) \\ \mathrm{cd}\end{array} \\ \mathrm{cv} & \text { conduction. } & \mathrm{Nu} & \text { Nusselt number. }\left(\mathrm{h} \cdot \mathrm{d}_{\mathrm{p}} / \mathrm{k}_{\mathrm{g}}\right) \\ \mathrm{e} & \text { convection. } & \mathrm{Re} & \text { Reynold number. }\left(\rho_{\mathrm{f}} \cdot \mathrm{U}_{\mathrm{f}} \cdot \mathrm{d}_{\mathrm{p}} / \mu_{\mathrm{f}}\right) \\ \mathrm{f} & \text { emulsion phase. } & \mathrm{Pr} & \text { Prandtl number. }\left(\mu_{\mathrm{f}} \mathrm{Cp} / \mathrm{k}_{\mathrm{g}}\right) \\ \mathrm{g} & \text { fluid. } & & \\ \mathrm{l} & \text { gas. } & & \\ \mathrm{mf} & \text { local. } & & \\ \mathrm{p} & \text { minimum fluidization. } & & \\ \mathrm{r} & \text { particle. } & & \\ \mathrm{s} & \text { radiation. } & & \\ \mathrm{t} & \text { solid. } & & \end{array}$




\section{References}

1. Gidaspow, D., and Ettehadieh B., "Fluidization in Two Dimensional Bed With Jets," part 2, Hydrodynamic Modeling, International and Engineering Chemistry Fundamentals, No.22, pp 193-201, 1983.

2. Basu, P. and Fraser S. A., "Circulating Fluidized Bed Boilers, Design and Operations," Butterworth-Heinemann, USA, pp55-94, 1991.

3. Mickley, J. S. M. and Williams, J. R., "Mechanism of Heat Transfer to Fluidized Beds," AIChE Journal, vol.1, pp374-384,1955.

4. Botterill, J. S. and Fairbanks, D. F., "The Mechanism of Heat Transfer to Gas Fluidized Beds,” Trans. Inst. Chemical Engineering vol.41, pp217-230, 1963.

5. Li Wang, Ping Wu and Xuezhi Ni, "Surface-Particle-Emulsion model of Heat Transfer Between a Fluidized Bed and an Immersed Surface," powder Technology, vol.149, pp127-138, 2005.

6. AL-Bajary, O.M.A., "Mathematical Model for Predicting the Heat Transfer Coefficient Between Shallow Gas Fluidized Bed and Vertical surfaces immersed in it," M.SC thesis, Mechanical Engineering Department, University of Mosul, 2002.

7. AL-Sabawi, A. W., "A Mathematical Model of Heat Transfer Coefficient Between Shallow Gas Fluidized Beds and Single Horizontal Immersed Tube," M.SC thesis, Mechanical Engineering Department, University of Mosul, 2004.

8. Gao, W.M., Kong, L.X. and Hodgson, P.D., "Computational Simulation of Gas Flow and Heat Transfer Near an Immersed Object in Fluidized Bed," Advanced in Engineering Software, 38, pp826-834, 2007.

9. Natale, F.D., Lancia, A. and Nigro, R.,"A single Particle Model for Surface-to-Bed Heat Transfer in Fluidized Beds, " Powder Technology, 187, pp 68-78, 2008.

10. Xuejun, Z., Ye Shichao and Pan, Xiaoheng, "The Local Heat Transfer Mathematical Model Between Vibrated Fluidized Bed and Horizontal Tubes," Experimental Thermal and Fluid Science, 32, pp 1279-1286, 2008.

11. Al-Ali B.M.A., "Fin Spacing Interaction in Fluidized Bed Heat Exchanger, " Ph.D Thesis, Department of Mechanical Engineering, the University of Aston in Birmingham, 1976.

12. Rasouli, S., Golriz, Z.R. and Hamidi, A.A.," Effect of Annular Fins on Heat Transfer of a Horizontal Immersed Tube in Bubbling Fluidized Beds," Powder Technology, 154, pp9-13, 2005.

13. Nima, M., Mostoufi, N., Hamidi, A. and Rahmat, S.G.," Investigation of Heat Transfer Between a Horizontal Tube and Gas-Solid Fluidized Bed," International Journal of Heat and Fluid Flow, 29, pp1504-1511, 2008.

14. Subramani, H.J., Balaiyya, M.B. and Miranda L.R.," Minimum Fluidization Velocity at Elevated Temperatures for Geldart's Group B Powder, " Experimental Thermal and Fluid Science, 32, pop166-173, 2007.

15. Ganzha, V.L.,, Upadhyay, S.N. and Saxena, S.C.,“ Mechanistic Theory for Heat Transfer Between Fluidized Beds of Large Particles and Immersed Surfaces," International Journal of Heat and Mass Transfer, vol.25,pp.1531-1540, 1982.

16. Karmers, H.,“ Heat Transfer From Spheres to Flowing Medium,” Applied Physics, vol.12, pp.61, 1946.

17. David, H., "Probability and Statistics For Students of computing," int. comm.., 2003.

18. Ziegler, E. N., Koppel, L.B. and Brazelton, W.T., INT. ENG. CHEM. Fundamental, 3,pp.94,1964. 
19. Baskakov A.P., Berg B.V., Goldobin J.HM., Vitt O.K., Fillippovsky N.F., Kirakosyan V.A. and Maskaev V.K., " Heat Transfer to Objects Immersed in Fluidized Beds," Powder Technology, No.8, PP273-282, 1973.

20. Gelperin, N.I. and Einstein, V.G.," Heat Transfer in Fluidized Beds,” fluidization, chapter 10, Academic press., 1971.

21. Vreedenberg H.A., "Heat Transfer Between a Fluidized Bed and Immersed Horizontal Tube," Chemical Engineering Science, vol.9, pp52-60, 1958.

22. Zabrodsky, k." Hydrodynamic and Heat Transfer in Fluidized Beds," chapter 10, M.I.T. press, 1966.

23. Grewal N.S.," A correlation for Maximum Heat Transfer Coefficient Between a Horizontal Tube and a Gas-Solid Fluidized Bed of Small Particle," International Journal of Heat and Mass Transfer, vol.9, pp377-384, 1982.

24. Chen, p. and David, C.T., "A Model of Heat Transfer Between Fluidized Bed and immersed surfaces,” Int. J. of Heat and Mass Transfer, vol.28,No.3,pp 675-682, 1985. 